\title{
Glubran $2^{\circledR}$ : A New Acrylic Glue for Neuroradiological Endovascular Use
}

\section{A Complementary Histological Study}

\author{
M. LEONARDI, P. CENNI, L. SIMONETTI, A. BOZZAO*, A. ROMANO*, M. BONAMINI*, \\ L.M. FANTOZZI*, G. FINI** \\ Servizio di Neuroradiologia, Ospedale Bellaria; Bologna; \\ *Cattedra di Neuroradiologia, **Cattedra di Chirurgia Maxillo-Facciale, II Facoltà di Medicina e Chirurgia, \\ Policlinico Sant'Andrea; Roma
}

Key words: acrylic glue, embolization, experimental neuroradiology

\section{Summary}

Two Landrace Large White swine underwent angiography by the femoral route.

In both cases, the superior left renal artery was embolized by injection of $2 \mathrm{ml}$ of Glubran $2^{\circledR}$, diluted with Lipiodol 1:1 thereby excluding the superior left kidney poles from blood flow.

During the follow-up period, neither pig presented any clinical symptom correlated to the embolization procedure. Case 1 was sacrificed after 30 days and case 2 after 60 days. Macroscopic and microscopic analysis was performed in both animals.

Long-term follow-up of the two cases after endovascular injection of Glubran $2^{\circledR}$ showed that the embolization procedure was well-tolerated by the swine in terms of clinical symptoms and histological findings. Arterial occlusion was stable and a reasonable quantity of scar tissue appeared between 30 and 60 days, surrounding the ischaemic tissue. This follow-up experimental study offers further evidence that Glubran $2^{\circledR}$ is a safe embolizing material for human use as far as its chemical activity is concerned.

\section{Introduction}

During the last few years, the Italian Ministry of Health has progressively prohibited the endovascular use of Histoacryl, the traditional embolizing agent used in arteriovenous malformations, because of its lack of a CE mark or FDA approval ${ }^{1}$. In this period two new agents appeared on the market: Onyx ${ }^{\circledR}$ (Onyx System, MTI - Micro Therapeutics Inc., San Clemente, CA, USA) and Glubran $2^{\circledR}$ (GEM Srl, Viareggio, Italy). Onyx ${ }^{\circledR}$ is a plastic material that is FDA and CE approved and has been used in AVM treatments with positive results ${ }^{2,3}$.

Glubran $2^{\circledR}$ was CE approved for neuroradiological endovascular use but had not been tested in vivo. In vitro haemocompatibility studies, undertaken to obtain the CE mark, were performed at the Pharmacology laboratories of the University of Padua. Tests were done on the plasma phase of haemostasis, determining partial thromboplastin time, prothrombin time, determining fibrinogen and its breakdown products, and on whole blood, measuring haemolysis, leucocyte count, leucocyte formula and platelet count. The results showed that during polymerization Glubran $2^{\circledR}$ has a haemostatic effect as it decreases the prothrombin time and does not break down fibrinogen. In contact with whole blood, the glue stimulates haemolysis during polymerization but thereafter has no significant influence on either the number of platelets or the leucocyte formula and number of leucocytes in whole human blood.

We undertook an experimental study using the sheep rete mirabile as an AVM model ${ }^{4,5}$ to compare the behaviour of Glubran $2^{\circledR}$ with that of Histoacryl at the time of injection. The animals were sacrificed at the end of the study thereby allowing histological analysis which demonstrated the angionecrosis produced by 


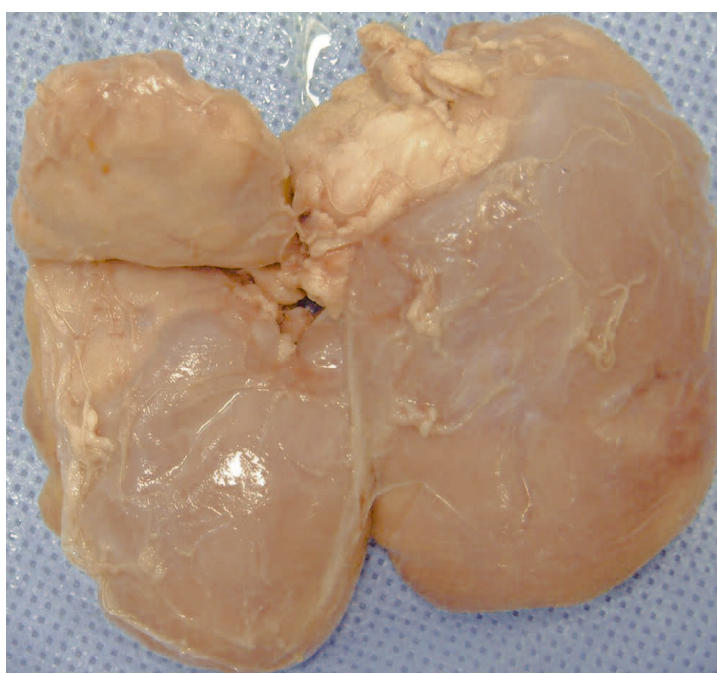

Figure 1 Left kidney. The superior pole presents a large yellowish-white infarcted area deforming the normal kidney margin.

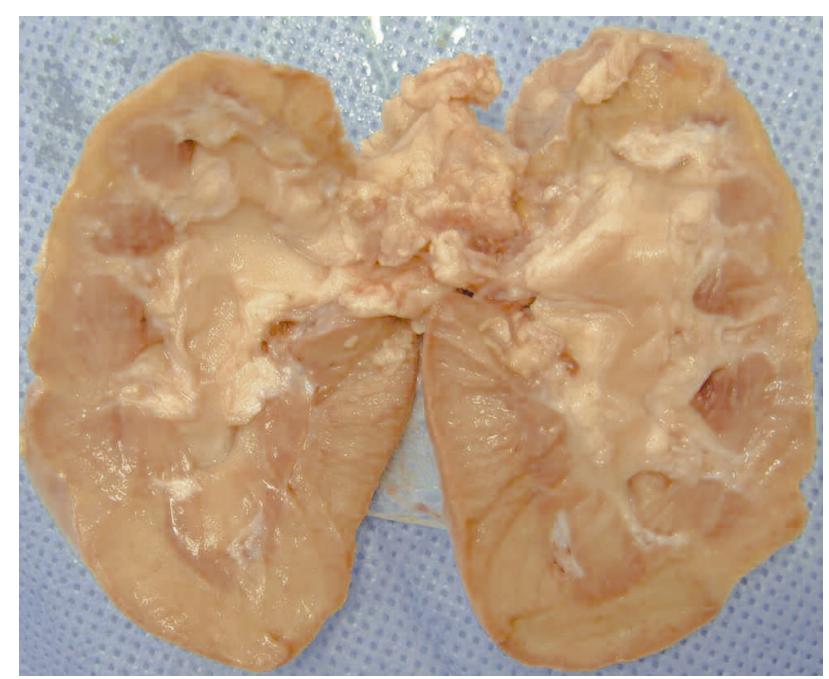

Figure 2 Left kidney opened flat. The infarcted area in the superior pole extends to much of the renal parenchyma deep into the pelvis.
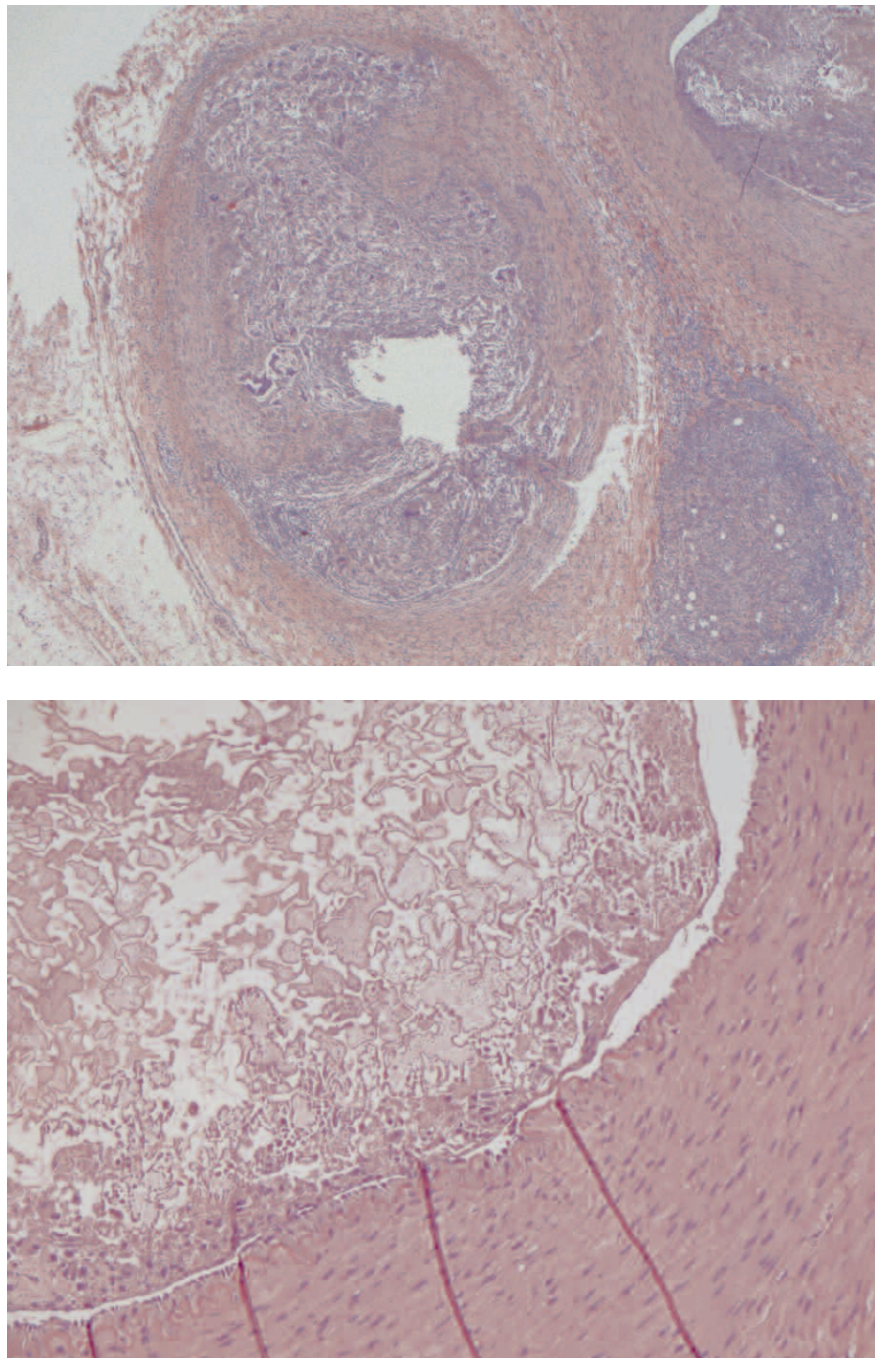

Figure 3 Transverse section of a main branch of the renal artery. The vascular lumen is partially occluded by a chronic inflammatory infiltrate containing many giant cells. The upper part of the image shows how an inflammatory reaction involves the whole thickness of the vascular wall. (x25, $\mathrm{H} \& \mathrm{E})$

Figure 4 Transverse section of a main branch of the renal artery. The vascular lumen is partially occluded by the synthetic glue which appears as an amorphous material. A slight chronic inflammatory infiltrate can be seen in the endothelial surface. The internal elastic membrane is visible in the vascular wall. (x200, H\&E) 


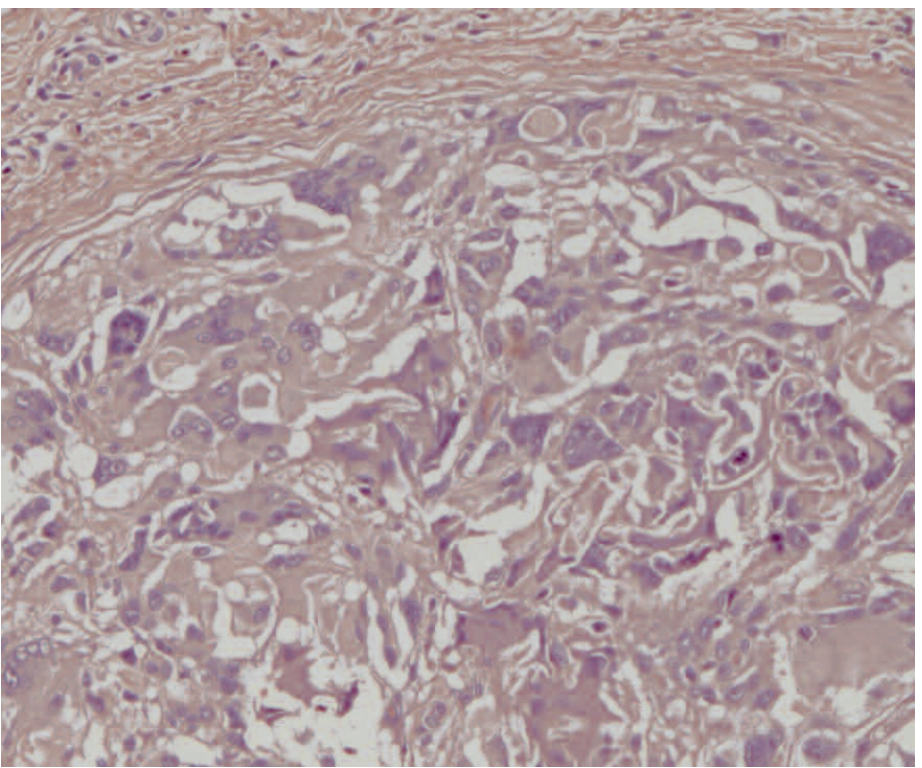

Figure 5 Detail of the chronic inflammatory infiltrate showing how it mainly comprises foreign body-like polynucleate giant cells. (x200, H\&E)

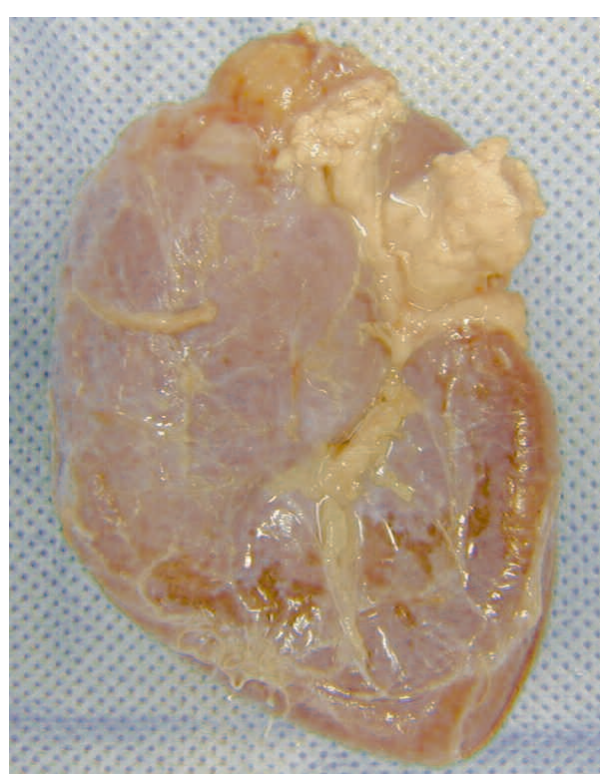

Figure 6 Left kidney. The superior pole contains a large yellowish-white infarcted area deforming the normal kidney margin.
Histoacryl but not by Glubran $2^{\circledR}$ injection. We have now done a study on swine to analyze the hystological reactions to endovascular injection of Glubran $2^{\circledR}$ thirty and sixty days after embolization.

\section{Material and Methods}

Two Landrace Large White swine, one female of $70.5 \mathrm{Kg}$ (case 1) and one male of $80 \mathrm{Kg}$ (case 2), under general anaesthesia (induction:
Tiletamine - Zolazepam i.m.; maintenance: intubation and ventilation with Isoflurane), underwent angiography by the femoral route, left femoral artery.

In both cases, the superior left renal artery was embolized by injection of $2 \mathrm{ml}$ of Glubran $2^{\circledR}$, diluted with Lipiodol 1:1 excluding the superior left kidney poles from blood flow. The kidney arteries were chosen because the kidney is physiologically compatible with all or-

A
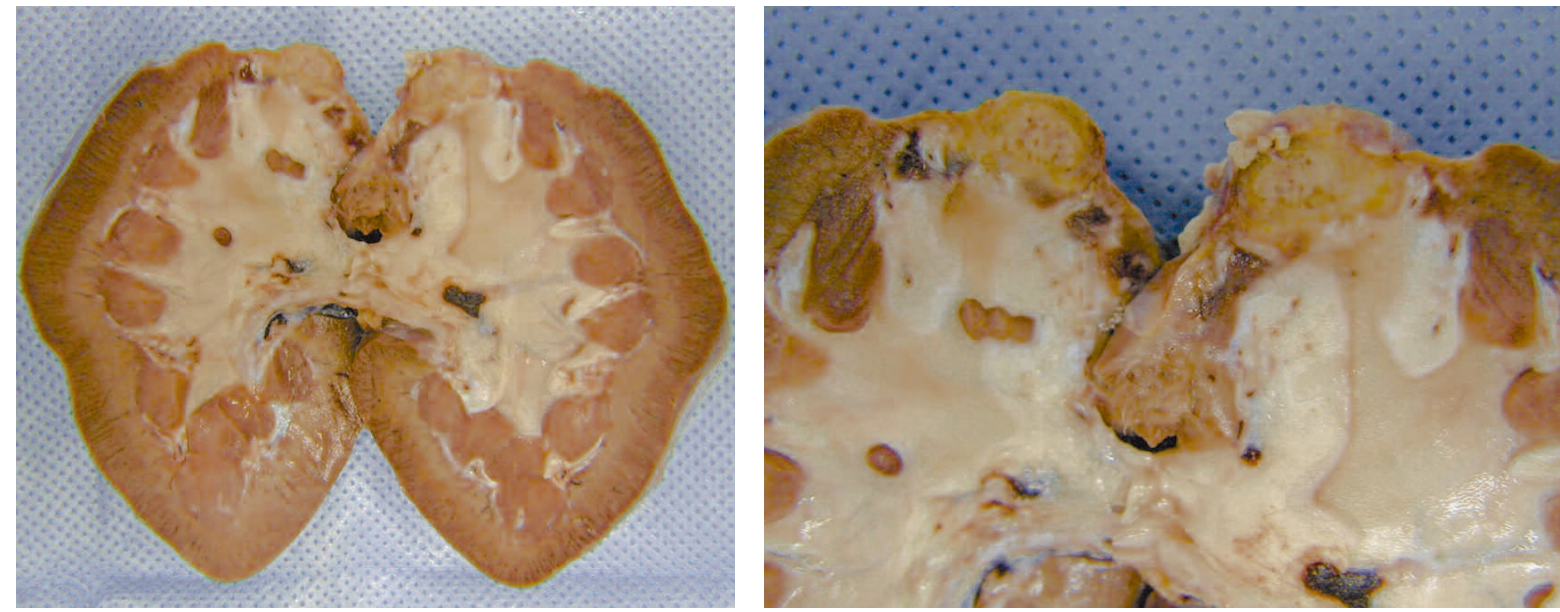

Figure 7 A,B) Left kidney opened flat. The infarcted area in the superior pole involves much of the renal parenchyma and is partly surrounded by a whitish fibrous scar reaction. 

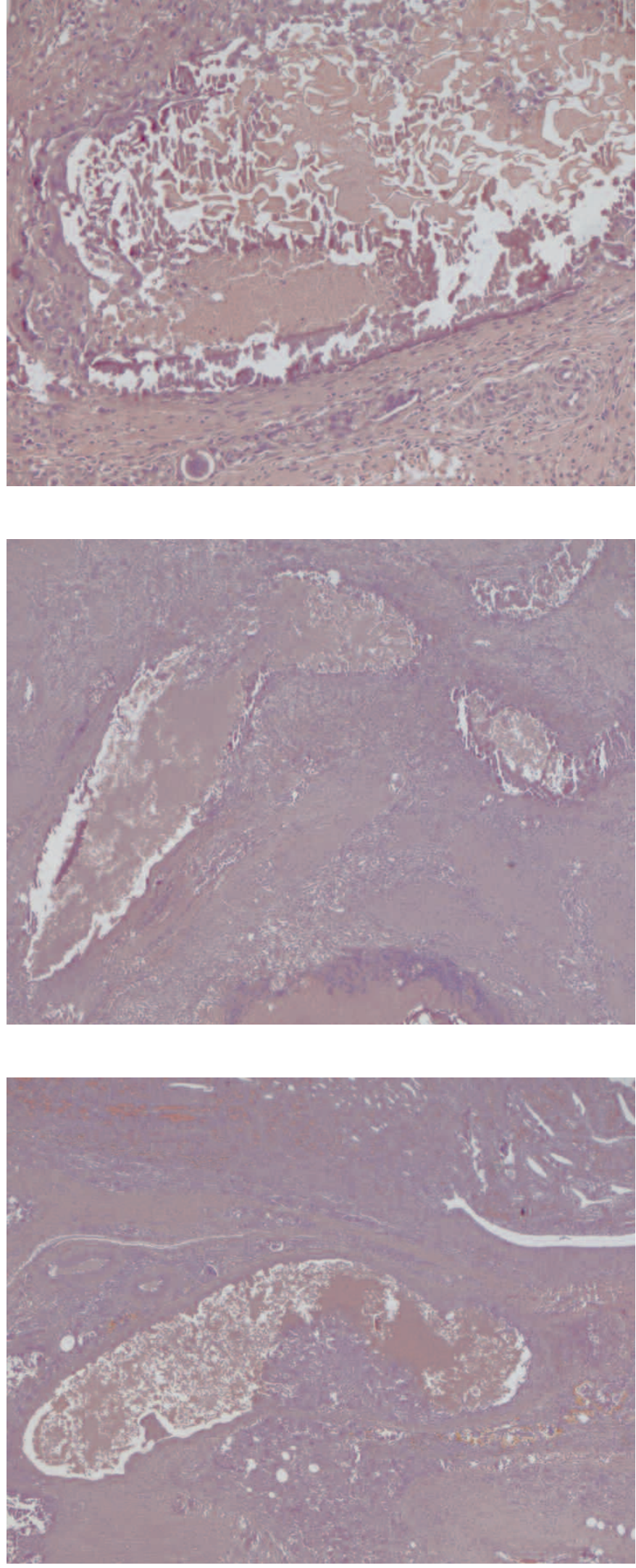

Figure 8 Transverse section of a main branch of the renal artery. The vascular lumen is occluded by the synthetic glue which appears as amorphous material. Note the mild chronic inflammatory infiltrate in the vascular wall. (x100, H\&E).

Figure 9 Longitudinal section of an intraparenchymal stretch of a renal artery branch. The vascular lumen is occluded by the synthetic glue which appears as amorphous material. (x25, H\&E).

Figure 10 Longitudinal section of an intraparenchymal stretch of a renal artery branch. The vascular lumen is occluded by the synthetic glue. The lower part of the image shows a focus of chronic inflammation extending into the vascular lumen. (x25, H\&E). 
Figure 11 Higher magnification of fig.10 Ma-22. The synthetic glue is seen on the right. The giant cell inflammatory reaction is seen on the left. Below, note the residual vascular wall. (x200, H\&E).

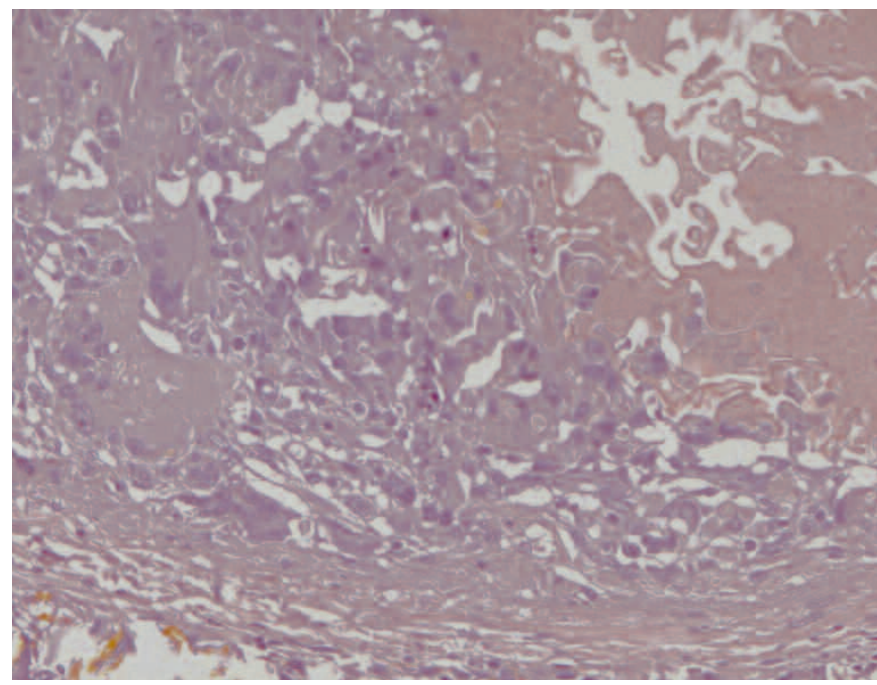

gans and the results can be of interest to fields other than neuroradiology (Glubran $2^{\circledR}$ is also used in general surgery and radiology). Moreover, the first studies on Histoacryl have been made on the kidney too ${ }^{6,7}$. During the followup period, neither pig presented any clinical symptom correlated to the embolization procedure. Haematological exams resulted all normal, before the procedure, immediately after and at the follow-up before sacrifice. Case 1 was sacrificed after 30 days and case 2 after 60 days. Macroscopic and microscopic analysis was performed in both animals.

\section{Results}

\section{Case 1}

At macroscopic analysis, the superior pole of the left kidney was a yellowish-white colour and clearly ischaemic (figure 1). After sagittal cut, the infarcted area was seen to extend deep into the pelvis (figure 2). At microscopic analysis, the renal artery appeared partially occluded by a chronic inflammatory reaction, with many giant cells (figure 3 ). The glue was clearly identifiable (figure 4) as amorphous material, surrounded by a slight endothelial inflammatory reaction with many polynucleate cells as commonly encountered in a foreign-body reaction (figure 5).

\section{Case 2}

At macroscopic analysis, the superior pole of the left kidney was a yellowish-white colour and clearly ischaemic (figure 6). After sagittal cut, the infarcted area was large (figure 7) partially surrounded by a whitish fibrous scar reaction. At microscopic analysis, the renal artery appeared completely occluded by the glue that was clearly identifiable as amorphous material, surrounded by a slight endothelial chronic inflammatory reaction (figure 8 ). The same findings were noted at a distal arterial branch (figure 9-11).

\section{Discussion}

The study of these two cases at 30 and 60 days after endovascular injection of Glubran $2{ }^{\circledR}$ showed that the embolization procedure was well-tolerated by the swine in terms of clinical symptoms and histological findings. Arterial occlusion was stable and scar tissue appeared between 30 and 60 days, surrounding the ischaemic tissue, in different quantities proportional to the elapsed time. No remote effect of the site of injection was evident. Following the positive outcome of the first animal study, we started to use Glubran $2^{\circledR}$ in the presurgical embolization of spine and skull tumors with good results ${ }^{8}$.

\section{Conclusions}

This study offers further evidence that Glubran $2^{\circledR}$ is a safe embolizing material for human use as far as its chemical activity is concerned. However, embolization with glue is difficult and dangerous -as we learned in more that twenty years use of Histoacryl- to administer and must be handled with care by trained neuroradiologists experienced in endovascular procedures. 


\section{References}

1 Ministero della Salute. Ufficio Dispositivi Medici: Revoca all'autorizzazione del dispositivo Histoacryl. Prot 0005014-P 16/10/2002.

2 Jahan R, Murayama Y et Al: Embolization of AVM with Onyx: clinico-pathological experience in 23 patients. Neurosurgery 48: 984-995, 2001.

3 Simonetti L, Cenni P et Al: Prime esperienze di embolizzazione di MAV cerebrali con Onyx. Rivista di Neuroradiologia 14 (Suppl 3): 251-256, 2001.

4 Leonardi M, Barbara C et Al: Glubran 2 ${ }^{\circledR}$ : A New Acrylic Glue for Neuroradiological Endovascular Use. Experimental Study on Animals. Interventional Neuroradiology 8: 245-250, 2002.

5 Leonardi M, Barbara C, Simonetti L: Glubran 2 ${ }^{\circledR}$ : A New Acrylic Glue Approved for Endovascular Use. ASNR 2002: 320.

6 Giuliani L, Carmignani G et Al: Renal Cancer Embolization with isobutyl-2-cyanoacrylate. Experimental study and first clinical applications. J Radiol Electrol Med Nucl 58: 419-425, 1977.
7 Gunther R, Schubert U et Al: Transcatheter embolization of the kidney with butyl-2-cyanoacrylate: experimental and clinical results. Cardiovasc Radiol 25: 101108, 1978.

8 Leonardi M, Simonetti L et Al: Embolizzazione prechirurgica di neoplasie della base cranica con colla acrilica (Glubran 2 ${ }^{\circledR}$ ): Prime esperienze. Atti del VII Congresso Nazionale della SIB. Milano, 2002.

Marco Leonardi, M.D.

Servizio di Neuroradiologia Ospedale Bellaria via Altura 3 40139 Bologna, Italy 